\title{
Synthesis, bioactivities and phloem uptake of dipeptide-chlorantraniliprole derivatives
}

\author{
Shijie Zheng ${ }^{1,2+}$, Xiaomin Lin ${ }^{1,2+}$, Hanxiang Wu ${ }^{1,2}$, Chen Zhao ${ }^{1,2^{*}}$ and Hanhong $\mathrm{Xu}^{1,2^{*}}$
}

\begin{abstract}
Phloem systemicity is a desirable property for insecticides to control sucking insects. However, the development of phloem systemic insecticides is challenging. One possible strategy is to link existed insecticides with endogenous substances so that the resulting conjugates can be transported by specific transporters into the phloem. In this study, novel dipeptide promoieties were introduced into chlorantraniliprole, which is an efficient and broad-spectrum anthranilic diamide insecticide without phloem mobility. Twenty-two new dipeptide-chlorantraniliprole conjugates have been synthesized. Systemic tests showed that all conjugates exhibited phloem mobility in Ricinus communis. In particular, compound $\mathbf{4 g}$ with alanyl-alanine dipeptide fragment was able to accumulate in phloem sap $(114.49 \pm 11.10 \mu \mathrm{M})$ in the form of its hydrolysis product $\mathbf{5 g}$. Results of bioassay showed that conjugates $\mathbf{4} \mathbf{g}$ and $\mathbf{5 g}$ were able to exhibit comparable insecticidal activity against Plutella xylostella L. and Spodoptera exigua compared to its parent compound chlorantraniliprole. This work demonstrated that the dipeptide structures were able to contribute to the improvement of the uptake and phloem mobility of chlorantraniliprole, and two phloem mobile conjugates with satisfactory in vivo insecticidal effect was obtained as new candidates for high-efficient insecticides.
\end{abstract}

Keywords: Chlorantraniliprole, Phloem-mobile pesticides, Dipeptide, Insecticidal activity

\section{Introduction}

With increasing demand for food and environmental safety, the use of pesticides is subjected to stringent restrictions. Furthermore, it was apparent to all that only a very small part of applied pesticide actually reached the sites of action, and the off-target portion became environmental pollutant $[1,2]$ which led to great public concern. Hence, the accurate and efficient utilization of agrochemicals was the focus of our research.

It has been demonstrated that coupling existing nonphloem mobile pesticide structures with endogenous substances, such as amino acids and saccharides, was

\footnotetext{
*Correspondence: zhaoc@scau.edu.cn; hhxu@scau.edu.cn

†Shijie Zheng and Xiaomin Lin contributed equally to this work

${ }^{1}$ State Key Laboratory for Conservation and Utilization of Subtropical

Argo-Bioresources, South China Agricultural University, Guangzhou, Guangdong, China

${ }^{2}$ Key Laboratory of Natural Pesticide and Chemical Biology, Ministry

of Education, South China Agricultural University, Guangzhou 510642, China
}

effective on improving their phloem mobility [3-14]. For example, a series of phloem mobile glucose-fipronil conjugates (GTF and GOF), glycinergic-fipronil conjugate (GlyF) and alanine ester-chlorantraniliprole conjugate were synthesized in our previous work, and their uptake process was proven to be mediated by active transport systems $[5,6,8]$. Such carrier-mediated transport strategy has been considered as a promising way for vectorizing agrochemicals, which can enhance bioavailability of pesticides [15].

Dipeptides and tripeptides can be transported into plant cells through peptide transporters, which were first discovered in Arabidopsis plants [16] as a $\mathrm{H}^{+}$-coupled transporter for oligopeptides [17, 18]. Similar facilitator transporters, such as oligopeptide transporter (PepT1 and PepT2), were also found in mammals to drive the uptake of di- and tri-peptides $[19,20]$. It has been proved that dipeptides could be used as promoieties to link with pharmacologically active substances and deliver prodrugs to target tissues [21-23]. Therefore, conjugating

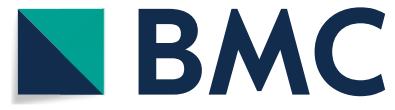

(c) The Author(s) 2020. This article is licensed under a Creative Commons Attribution 4.0 International License, which permits use, sharing, adaptation, distribution and reproduction in any medium or format, as long as you give appropriate credit to the original author(s) and the source, provide a link to the Creative Commons licence, and indicate if changes were made. The images or other third party material in this article are included in the article's Creative Commons licence, unless indicated otherwise in a credit line to the material. If material is not included in the article's Creative Commons licence and your intended use is not permitted by statutory regulation or exceeds the permitted use, you will need to obtain permission directly from the copyright holder. To view a copy of this licence, visit http://creativeco mmons.org/licenses/by/4.0/. The Creative Commons Public Domain Dedication waiver (http://creativecommons.org/publicdomain/ zero/1.0/) applies to the data made available in this article, unless otherwise stated in a credit line to the data. 
dipeptide structures with existing pesticides is expected to be another potential strategy to obtain new candidates for phloem-mobile pesticides, which could enhance the efficiency and reduce the consumption of pesticides.

\section{Materials and methods Chemistry}

A series of new dipeptide-chlorantraniliprole conjugates were synthesized by coupling chlorantraniliprole with different dipeptides as shown in Scheme 1. Reacting intermediate $\mathbf{1}$ with corresponding amino acid methyl ester hydrochlorides led to $\mathbf{2 a - b}[24,25]$. Then, to a solution of compound $\mathbf{2 a}$ or $\mathbf{2 b}$ in tetrahydrofuran (THF), lithium hydroxide was slowly added. After being stirred for $2 \mathrm{~h}$, the reaction mixture was acidified to $\mathrm{pH}=3$ with $1 \mathrm{M}$ hydrochloric acid $(\mathrm{HCl})$, and the organic phase was concentrated under reduced pressure to obtain $\mathbf{3 a}$ and $\mathbf{3 b}$ [26]. To a solution of $\mathbf{3 a}$ or $\mathbf{3 b}$ in dry dichloromethane were sequentially added amino acid hydrochlorides, 1-(3-dimethylaminopropyl)-3-ethylcarbodiimide hydrochloride (EDCI), and $N, N$-dimethyl-4-aminopyridine (DMAP). The mixture was stirred at room temperature overnight. After evaporating the solvent in vacuo, the residue was purified by flash column chromatography<smiles>[R10]CN(C)C(=O)c1cc(Cl)cc(C)c1NC(=O)c1cc(Br)nn1-c1ncccc1Cl</smiles><smiles>[R1]CN1CC[C@@H](C)C1</smiles>

$3 a-b$<smiles>[R]C(NC(=O)C([R])NC(=O)c1cc(Cl)cc(C)c1NC(=O)c1cc(Br)nn1-c1ncccc1Cl)C(=O)O</smiles><smiles>[Y10][X]</smiles>
4a, 5a $\mathbf{R}^{1}=\mathrm{H}, \mathbf{R}^{2}=\mathrm{H}$
$\mathbf{4 b}, \mathbf{5 b} \quad \mathbf{R}^{\mathbf{1}}=\mathrm{H}, \mathbf{R}^{\mathbf{2}}=\mathrm{CH}_{3}$
4c, $5 \mathbf{c} \quad \mathbf{R}^{1}=\mathrm{H}, \mathbf{R}^{2}=i$-Bu
4d, $\mathbf{5 d} \mathbf{R}^{\mathbf{1}}=\mathrm{H}, \mathbf{R}^{\mathbf{2}}=i$-Pr
4e, 5e $\mathbf{R}^{\mathbf{1}}=\mathrm{H}, \mathbf{R}^{\mathbf{2}}=\mathrm{CH}_{2} \mathrm{OH}$
4f, 5f $\mathbf{R}^{\mathbf{1}}=\mathrm{CH}_{3}, \mathbf{R}^{\mathbf{2}}=\mathrm{H}$
4 g, 5 g $\mathbf{R}^{1}=\mathrm{CH}_{3}, \mathbf{R}^{2}=\mathrm{CH}_{3}$
4h, $\mathbf{5 h} \quad \mathbf{R}^{\mathbf{1}}=\mathrm{CH}_{3}, \mathbf{R}^{\mathbf{2}}=\mathrm{CH}_{2} \mathrm{CH}_{2} \mathrm{SCH}_{3}$
4i, 5i $\quad \mathbf{R}^{\mathbf{1}}=\mathrm{CH}_{3}, \mathbf{R}^{\mathbf{2}}=\mathrm{CH}_{2} \mathrm{COOCH}_{3}$
$\mathbf{4 j}, \mathbf{5} \mathbf{j} \quad \mathbf{R}^{\mathbf{1}}=\mathrm{CH}_{3}, \mathbf{R}^{\mathbf{2}}=\mathrm{Bn}$
$4 \mathbf{k}, \mathbf{5 k} \quad \mathbf{R}^{1}=\mathrm{CH}_{3}, \mathbf{R}^{2}=p$-cresol

\section{5a-k}

Scheme 1 Synthetic route of target compounds $\mathbf{4 a - k}$ and $\mathbf{5 a - k}$. General reaction conditions: $\mathbf{a} \mathrm{TEA}, \mathrm{CH}_{2} \mathrm{Cl}_{2}$, room temperature to $45^{\circ} \mathrm{C}, 8$ $\mathrm{h} ; \mathbf{b} \mathrm{LiOH}, \mathrm{THF} / \mathrm{H}_{2} \mathrm{O}, \mathrm{O}^{\circ} \mathrm{C}$ to room temperature, $2 \mathrm{~h}$; c NMM, EDCl, $\mathrm{DMAP}, \mathrm{CH}_{2} \mathrm{Cl}_{2}$, room temperature, overnight; $\mathbf{d} \mathrm{LiOH}, \mathrm{THF} / \mathrm{H}_{2} \mathrm{O}, 0^{\circ} \mathrm{C}$ to room temperature, $2 \mathrm{~h}$ 
(silica gel, petroleum ether/ethyl acetate $=2: 1, \mathrm{v} / \mathrm{v}$ ) to afford compounds $\mathbf{4 a - k}$ [27]. Compounds $\mathbf{5 a}-\mathbf{k}$ were prepared with similar hydrolysis reactions as used to prepare compounds $\mathbf{3 a}$ and $\mathbf{3 b}$. Purifications of the crude products were performed via flash column chromatography (silica gel, petroleum ether/ethyl acetate/acetic acid $=1: 1: 0.005, \mathrm{v} / \mathrm{v} / \mathrm{v})$.

Reagents were purchased from commercial resources and were used without further purification unless otherwise stated. All reactions were carried out under nitrogen atmosphere with dry solvents and were monitored by thin-layer chromatography (TLC) analysis using silica gel GF254 thin-layer plates, and spots were visualized with a ZF-20D ultraviolet (UV) analyzer. Column chromatography purification was performed over silica gel (200-300 mesh, Qingdao Marine Chemical Ltd.). ${ }^{1} \mathrm{H}$ fourier transform nuclear magnetic resonance (FT-NMR) spectra were measured with a Bruker AV-600 MHz instrument and calibrated using residual un-deuterated solvents as internal references $\left(\mathrm{CDCl}_{3}: \delta=7.26 \mathrm{ppm}\right.$ for ${ }^{1} \mathrm{H}$ NMR; DMSO- $d_{6}: \delta=2.50 \mathrm{ppm}$ for ${ }^{1} \mathrm{H}$ NMR) [28]. Multiplicities were reported as follows: singlet (s), doublet (d), triplet (t), quartet (q), doublet of doublets (dd), and multiplet $(\mathrm{m})$. Coupling constants were reported as $J$ values in hertz. MS data were obtained using the Waters SYN$\mathrm{APT}^{\mathrm{TM}}$ mass spectrometry.

\section{General procedure for synthesis of compounds $2 a-b$}

To a dry round-bottomed flask containing a solution of dry triethylamine $(12 \mathrm{mmol})$ in $20 \mathrm{~mL}$ anhydrous dichloromethane $\left(\mathrm{CH}_{2} \mathrm{Cl}_{2}\right)$, glycine methyl ester hydrochloride $(1.50 \mathrm{~g}, 12 \mathrm{mmol})$ or L-alanine methyl ester hydrochloride $(1.67 \mathrm{~g}, 12 \mathrm{mmol})$ was added under nitrogen, respectively. The reaction mixture was stirred for $30 \mathrm{~min}$ at room temperature. A solution of compound $\mathbf{1}(10 \mathrm{mmol})$ in anhydrous $\mathrm{CH}_{2} \mathrm{Cl}_{2}$ was then added dropwise under nitrogen. The suspension was warmed up to $45{ }^{\circ} \mathrm{C}$ and stirred for $8 \mathrm{~h}$ until TLC indicated complete consumption of the starting materials. The reaction mixture was cooled to room temperature, followed by the addition of water $(10 \mathrm{~mL})$. The mixture was extracted with ethyl acetate $(3 \times 10 \mathrm{~mL})$. The combined organic layer was dried over $\mathrm{Na}_{2} \mathrm{SO}_{4}$, filtered and concentrated by rotary evaporation to obtain $\mathbf{2 a}$ and $\mathbf{2 b}$, which were used in the next step without purification.

\section{General procedure for synthesis of compounds $3 a-b$ [29]}

Compound $2 \mathbf{a}$ or $\mathbf{2 b}(5 \mathrm{mmol})$ was added in the mixed solvent of THF and $\mathrm{H}_{2} \mathrm{O}$ at $0^{\circ} \mathrm{C}$, then lithium hydroxide $(0.63 \mathrm{~g}, 15 \mathrm{mmol})$ was slowly added. After being stirred for $2 \mathrm{~h}$, the reaction mixture was acidified to $\mathrm{pH}=2$ with $\mathrm{HCl}(1 \mathrm{M})$. The organic phase was removed by rotary evaporation. The residual aqueous solution was extracted with ethyl acetate $(3 \times 20 \mathrm{~mL})$, and the combined organic extract was washed with $\mathrm{H}_{2} \mathrm{O}(3 \times 20 \mathrm{~mL})$, dried over $\mathrm{Na}_{2} \mathrm{SO}_{4}$, then concentrated under reduced pressure to obtain crude product of $\mathbf{3} \mathbf{a}$ and $\mathbf{3} \mathbf{b}$ which was used in the next step directly.

\section{General procedure for synthesis of compounds $4 a-k$ [27]}

To a solution of $\mathbf{3 a}$ or $\mathbf{3 b}(10 \mathrm{mmol})$ in dry $\mathrm{CH}_{2} \mathrm{Cl}_{2}(10$ $\mathrm{mL}$ ) were sequentially added amino acid hydrochlorides (13 mmol), EDCI $(2.88 \mathrm{~g}, 15 \mathrm{mmol})$, and DMAP $(0.61 \mathrm{~g}$, $5.0 \mathrm{mmol})$. The mixture was stirred at room temperature for overnight, then diluted with $\mathrm{H}_{2} \mathrm{O}(10 \mathrm{~mL})$, acidified with citric acid $(10 \%)$ and extracted with $\mathrm{CH}_{2} \mathrm{Cl}_{2}(3 \times 10$ $\mathrm{mL}$ ). The combined organic layers were washed with saturated $\mathrm{NaHCO}_{3}$ aq. Solution and dried over $\mathrm{Na}_{2} \mathrm{SO}_{4}$, filtered, and concentrated. The residue was purified by flash column chromatography (silica gel, petroleum ether/ ethyl acetate $=2: 1, \mathrm{v} / \mathrm{v}$ ) to afford compounds of $\mathbf{4 a}-\mathbf{k}$.

Methyl\{2-[3-bromo-1-(3-chloropyridin-2-yl)-1H-pyrazole-5-carboxamido]-5-chloro-3-methylbenzoyl)glycylglycinate (4a) White solid in $79 \%$ yield; ${ }^{1} \mathrm{H}$ NMR (600 $\left.\mathrm{MHz}, \mathrm{DMSO}-d_{6}\right): \delta 10.26(\mathrm{~s}, 1 \mathrm{H}), 8.66(\mathrm{~s}, 1 \mathrm{H}), 8.47(\mathrm{dd}$, $J=4.7,1.5 \mathrm{~Hz}, 1 \mathrm{H}), 8.19(\mathrm{t}, J=6.0 \mathrm{~Hz}, 1 \mathrm{H}), 8.15(\mathrm{dd}$, $J=8.1,1.5 \mathrm{~Hz}, 1 \mathrm{H}), 7.59(\mathrm{dd}, J=8.1,4.7 \mathrm{~Hz}, 1 \mathrm{H}), 7.51(\mathrm{~d}$, $J=2.4 \mathrm{~Hz}, 1 \mathrm{H}), 7.49(\mathrm{~s}, 1 \mathrm{H}), 7.31(\mathrm{~s}, 1 \mathrm{H}), 3.83(\mathrm{~d}, J=5.9$ $\mathrm{Hz}, 2 \mathrm{H}), 3.77(\mathrm{~d}, J=5.8 \mathrm{~Hz}, 2 \mathrm{H}), 3.62(\mathrm{~s}, 3 \mathrm{H}), 2.16(\mathrm{~s}, 3 \mathrm{H})$. ${ }^{13} \mathrm{C}$ NMR $\left(151 \mathrm{MHz}\right.$, DMSO- $\left.d_{6}\right): \delta 172.55,172.48,172.31$, $165.79,165.72,156.03,148.84,147.53,139.68,139.16$, $136.15,131.77,131.41,128.33,127.22,127.04,126.31$, $111.14,61.84,54.96,49.05,18.11$. ESI-HRMS calcd. For $\mathrm{C}_{22} \mathrm{H}_{18} \mathrm{BrCl}_{2} \mathrm{~N}_{6} \mathrm{O}_{5}:[\mathrm{M}-\mathrm{H}]^{-}$594.9899, found 594.9893 .

Methyl\{2-[3-bromo-1-(3-chloropyridin-2-yl)-1H-pyrazole-5-carboxamido)-5-chloro-3-methylbenzoyl)glycyl-L-alaninate (4b) White solid in $71 \%$ yield; ${ }^{1} \mathrm{H}$ NMR $\left(600 \mathrm{MHz}\right.$, DMSO- $\left.d_{6}\right): \delta 10.24(\mathrm{~s}, 1 \mathrm{H}), 8.54(\mathrm{t}, J=5.8$ $\mathrm{Hz}, 1 \mathrm{H}), 8.49(\mathrm{~d}, J=4.6 \mathrm{~Hz}, 1 \mathrm{H}), 8.31(\mathrm{~d}, J=6.9 \mathrm{~Hz}, 1 \mathrm{H})$, $8.16(\mathrm{~d}, J=7.9 \mathrm{~Hz}, 1 \mathrm{H}), 7.60(\mathrm{dd}, J=8.2,4.7 \mathrm{~Hz}, 1 \mathrm{H})$, $7.49(\mathrm{~d}, J=15.7 \mathrm{~Hz}, 2 \mathrm{H}), 7.34(\mathrm{~s}, 1 \mathrm{H}), 4.31(\mathrm{q}, J=7.2 \mathrm{~Hz}$, $1 \mathrm{H}), 3.85-3.73(\mathrm{~m}, 2 \mathrm{H}), 3.62(\mathrm{~s}, 3 \mathrm{H}), 2.16(\mathrm{~s}, 3 \mathrm{H}), 1.27$ $(\mathrm{d}, J=7.2 \mathrm{~Hz}, 3 \mathrm{H}) .{ }^{13} \mathrm{C}$ NMR $\left(151 \mathrm{MHz}, \mathrm{DMSO}-d_{6}\right): \delta$ $173.11,167.81,167.62,155.99,148.79,146.78,139.13$, $139.08,138.41,133.56,132.17,132.11,130.59,128.87$, $128.09,125.69,125.05,110.88,52.68,48.37,43.26,18.96$, 18.14. ESI-HRMS calcd. For $\mathrm{C}_{23} \mathrm{H}_{20} \mathrm{BrCl}_{2} \mathrm{~N}_{6} \mathrm{O}_{5}:[\mathrm{M}-\mathrm{H}]^{-}$ 609.0056, found 609.0053.

Methyl \{2-[3-bromo-1-(3-chloropyridin-2-yl)-1H-pyrazole-5-carboxamido)-5-chloro-3-methylbenzoyl)glycyl-L-leucinate (4c) White solid in 65\% yield; ${ }^{1} \mathrm{H}$ NMR $\left(600 \mathrm{MHz}, \mathrm{DMSO}-d_{6}\right): \delta 10.26(\mathrm{~s}, 1 \mathrm{H}), 8.53(\mathrm{t}, J=5.9 \mathrm{~Hz}$, $1 \mathrm{H}), 8.49(\mathrm{~d}, J=4.7 \mathrm{~Hz}, 1 \mathrm{H}), 8.28(\mathrm{~d}, J=7.8 \mathrm{~Hz}, 1 \mathrm{H}), 8.16$ 
$(\mathrm{d}, J=8.0 \mathrm{~Hz}, 1 \mathrm{H}), 7.60(\mathrm{dd}, J=8.1,4.7 \mathrm{~Hz}, 1 \mathrm{H}), 7.50-7.46$ (m, 2H), $7.34(\mathrm{~s}, 1 \mathrm{H}), 4.32$ (ddd, $J=9.8,7.8,5.1 \mathrm{~Hz}, 1 \mathrm{H}$ ), 3.83 (dd, $J=16.6,6.0 \mathrm{~Hz}, 1 \mathrm{H}), 3.76(\mathrm{dd}, J=16.6,5.8 \mathrm{~Hz}$, $1 \mathrm{H}), 3.61(\mathrm{~s}, 3 \mathrm{H}), 2.16(\mathrm{~s}, 3 \mathrm{H}), 1.63-1.51(\mathrm{~m}, 2 \mathrm{H}), 1.52-$ $1.47(\mathrm{~m}, 1 \mathrm{H}), 0.86(\mathrm{~d}, J=6.5 \mathrm{~Hz}, 3 \mathrm{H}), 0.83(\mathrm{~d}, J=6.4 \mathrm{~Hz}$, $3 \mathrm{H}) .{ }^{13} \mathrm{C}$ NMR (151 MHz, DMSO- $\left.d_{6}\right): \delta 173.30,169.24$, $166.51,156.21,148.70,147.54,139.88,139.77,139.29$, $135.67,131.99,131.40,128.15,127.29,127.02,126.16$, $111.20,52.34,50.73,42.55,40.42,24.65,23.16,21.79$, 18.15. ESI-HRMS calcd. For $\mathrm{C}_{26} \mathrm{H}_{26} \mathrm{BrCl}_{2} \mathrm{~N}_{6} \mathrm{O}_{5}:[\mathrm{M}-\mathrm{H}]^{-}$ 651.0525 , found 651.0514 .

Methyl\{2-[3-bromo-1-(3-chloropyridin-2-yl)-1H-pyrazole-5-carboxamido)-5-chloro-3-methylbenzoyl)glycyl-L-valinate (4d) White solid in $58 \%$ yield; ${ }^{1} \mathrm{H}$ NMR $\left(600 \mathrm{MHz}, \mathrm{DMSO}-d_{6}\right): \delta 9.99(\mathrm{~s}, 1 \mathrm{H}), 8.41(\mathrm{dd}, J=4.7$, $1.6 \mathrm{~Hz}, 1 \mathrm{H}), 7.82(\mathrm{dd}, J=8.1,1.6 \mathrm{~Hz}, 1 \mathrm{H}), 7.36-7.32(\mathrm{~m}$, $2 \mathrm{H}), 7.27(\mathrm{~d}, J=1.7 \mathrm{~Hz}, 1 \mathrm{H}), 7.23(\mathrm{t}, J=5.2 \mathrm{~Hz}, 1 \mathrm{H}), 7.03$ $(\mathrm{s}, 1 \mathrm{H}), 6.67(\mathrm{~d}, J=8.7 \mathrm{~Hz}, 1 \mathrm{H}), 4.53(\mathrm{dd}, J=8.7,5.0 \mathrm{~Hz}$, $1 \mathrm{H}), 4.04(\mathrm{dd}, J=7.2,5.2 \mathrm{~Hz}, 2 \mathrm{H}), 3.74(\mathrm{~s}, 3 \mathrm{H}), 2.18(\mathrm{~s}$, $3 \mathrm{H}), 2.14(\mathrm{dd}, J=11.9,6.9 \mathrm{~Hz}, 1 \mathrm{H}), 0.91(\mathrm{~d}, J=6.9 \mathrm{~Hz}$, $6 \mathrm{H}) .{ }^{13} \mathrm{C}$ NMR (151 MHz, DMSO- $\left.d_{6}\right): \delta 172.90,172.39$, $165.68,156.03,148.83,147.53,139.69,139.17,135.98$, $131.84,131.38,128.31,127.22,127.04,126.33,111.11$, $57.55,52.18,49.18,30.61,19.47,18.75,18.52,18.12$. ESIHRMS calcd. For $\mathrm{C}_{25} \mathrm{H}_{24} \mathrm{BrCl}_{2} \mathrm{~N}_{6} \mathrm{O}_{5}:[\mathrm{M}-\mathrm{H}]^{-}$637.0369, found 637.0359.

Methyl\{2-[3-bromo-1-(3-chloropyridin-2-yl)-1H-pyrazole-5-carboxamido)-5-chloro-3-methylbenzoyl)glycyl-L-serinate (4e) White solid in $64 \%$ yield; ${ }^{1} \mathrm{H}$ NMR $\left(600 \mathrm{MHz}, \mathrm{DMSO}-d_{6}\right): \delta 10.24(\mathrm{~s}, 1 \mathrm{H}), 8.52(\mathrm{t}, J=6.1 \mathrm{~Hz}$, $1 \mathrm{H}), 8.49(\mathrm{~d}, J=4.7 \mathrm{~Hz}, 1 \mathrm{H}), 8.28(\mathrm{~d}, J=7.8 \mathrm{~Hz}, 1 \mathrm{H}), 8.16$ $(\mathrm{d}, J=8.0 \mathrm{~Hz}, 1 \mathrm{H}), 7.61(\mathrm{dd}, J=7.3,4.2 \mathrm{~Hz}, 1 \mathrm{H}), 7.50(\mathrm{~s}$, $1 \mathrm{H}), 7.44(\mathrm{~s}, 1 \mathrm{H}), 7.36(\mathrm{~s}, 1 \mathrm{H}), 5.09(\mathrm{t}, J=5.7 \mathrm{~Hz}, 1 \mathrm{H})$, $4.39(\mathrm{q}, J=5.3 \mathrm{~Hz}, 1 \mathrm{H}), 3.85(\mathrm{qd}, J=16.7,5.9 \mathrm{~Hz}, 2 \mathrm{H})$, $3.71(\mathrm{dt}, J=11.0,5.4 \mathrm{~Hz}, 1 \mathrm{H}), 3.64(\mathrm{~s}, 3 \mathrm{H}), 3.63-3.59$ (m, 1H), $2.16(\mathrm{~s}, 3 \mathrm{H}) .{ }^{13} \mathrm{C}$ NMR (151 MHz, DMSO- $\left.d_{6}\right)$ : $\delta 170.89,168.90,168.11,156.37,148.71,146.63,139.37$, $139.00,138.35,133.33,132.29,131.69,131.29,129.07$, $125.88,125.38,111.16,62.13,54.69,52.81,43.45,29.68$, 18.76. ESI-HRMS calcd. For $\mathrm{C}_{23} \mathrm{H}_{20} \mathrm{BrCl}_{2} \mathrm{~N}_{6} \mathrm{O}_{5}:[\mathrm{M}-\mathrm{H}]^{-}$ 625.0005, found 625.0007.

Methyl\{2-[3-bromo-1-(3-chloropyridin-2-yl)-1H-pyrazole-5-carboxamido)-5-chloro-3-methylbenzoyl)-L-alanylglycinate (4f) White solid in $76 \%$ yield; ${ }^{1} \mathrm{H}$ NMR $\left(600 \mathrm{MHz}, \mathrm{DMSO}-d_{6}\right): \delta 10.24(\mathrm{~s}, 1 \mathrm{H}), 8.49(\mathrm{~s}, 2 \mathrm{H}), 8.19$ (s, $1 \mathrm{H}), 8.16(\mathrm{dd}, J=8.1,1.5 \mathrm{~Hz}, 1 \mathrm{H}), 7.61$ (dd, $J=8.1,4.7$ $\mathrm{Hz}, 1 \mathrm{H}), 7.52$ (dd, $J=2.5,0.7 \mathrm{~Hz}, 2 \mathrm{H}), 7.35(\mathrm{~s}, 1 \mathrm{H}), 4.31$ $(\mathrm{s}, 1 \mathrm{H}), 3.82(\mathrm{~d}, J=5.9 \mathrm{~Hz}, 2 \mathrm{H}), 3.63(\mathrm{~s}, 3 \mathrm{H}), 2.18(\mathrm{~s}, 3 \mathrm{H})$, $1.21(\mathrm{~d}, J=7.2 \mathrm{~Hz}, 3 \mathrm{H}) .{ }^{13} \mathrm{C}$ NMR $\left(151 \mathrm{MHz}\right.$, DMSO- $\left.d_{6}\right)$ : $\delta 173.06,170.59,166.07,156.12,148.80,147.54,139.77$,
139.71, 138.92, 135.97, 131.80, 131.75, 131.33, 128.27, 127.25, 127.05, 126.42, 111.10, 52.14, 49.23, 41.00, 18.11, 18.07. ESI-HRMS calcd. For $\mathrm{C}_{23} \mathrm{H}_{20} \mathrm{BrCl}_{2} \mathrm{~N}_{6} \mathrm{O}_{5}:[\mathrm{M}-\mathrm{H}]^{-}$ 609.0056, found 609.0042.

Methyl\{2-[3-bromo-1-(3-chloropyridin-2-yl)-1H-pyrazole-5-carboxamido)-5-chloro-3-methylbenzoyl)-L-alanyl-L-alaninate (4g) White solid in $76 \%$ yield; ${ }^{1} \mathrm{H}$ NMR $\left(600 \mathrm{MHz}, \mathrm{DMSO}-d_{6}\right): \delta 10.25(\mathrm{~s}, 1 \mathrm{H}), 8.49(\mathrm{dd}, J=4.7$, $1.6 \mathrm{~Hz}, 1 \mathrm{H}), 8.37(\mathrm{~d}, J=4.9 \mathrm{~Hz}, 1 \mathrm{H}), 8.27(\mathrm{~d}, J=7.4 \mathrm{~Hz}$, $1 \mathrm{H}), 8.16(\mathrm{dd}, J=8.1,1.5 \mathrm{~Hz}, 1 \mathrm{H}), 7.60$ (dd, $J=8.1,4.7$ $\mathrm{Hz}, 1 \mathrm{H}), 7.50(\mathrm{dd}, J=7.3,2.3 \mathrm{~Hz}, 2 \mathrm{H}), 7.36(\mathrm{~s}, 1 \mathrm{H}), 7.36$ (s, 1H), 4.39-4.32 (m, 1H), 4.31-4.25 (m, $J=7.3,2.7 \mathrm{~Hz}$, $1 \mathrm{H}), 3.62(\mathrm{~s}, 3 \mathrm{H}), 2.18(\mathrm{~s}, 3 \mathrm{H}), 1.26(\mathrm{~d}, J=7.3 \mathrm{~Hz}, 3 \mathrm{H})$, $1.21(\mathrm{~d}, J=7.2 \mathrm{~Hz}, 3 \mathrm{H}) .{ }^{13} \mathrm{C}$ NMR $\left(151 \mathrm{MHz}, \mathrm{DMSO}-d_{6}\right)$ : $\delta 173.30,172.41,165.83,156.06,148.80,147.52,139.77$, $139.69,139.06,135.99,135.86,131.83,131.37,128.27$, 127.24, 127.02, 126.44, 126.35, 111.14, 52.31, 49.21, 18.41, 18.14, 17.51. ESI-HRMS calcd. For $\mathrm{C}_{24} \mathrm{H}_{22} \mathrm{BrCl}_{2} \mathrm{~N}_{6} \mathrm{O}_{5}$ : $[\mathrm{M}-\mathrm{H}]^{-}$623.0212, found 623.0209.

Methyl\{2-[3-bromo-1-(3-chloropyridin-2-yl)-1H-pyrazole-5-carboxamido)-5-chloro-3-methylbenzoyl)-L-alanyl-L-methioninate $(4 \mathrm{~h})$ White solid in $65 \%$ yield; ${ }^{1} \mathrm{H}$ NMR $\left(600 \mathrm{MHz}\right.$, DMSO- $\left.d_{6}\right): \delta 10.25(\mathrm{~s}, 1 \mathrm{H}), 8.48(\mathrm{dd}$, $J=4.7,1.5 \mathrm{~Hz}, 1 \mathrm{H}), 8.40(\mathrm{~d}, J=7.0 \mathrm{~Hz}, 1 \mathrm{H}), 8.31(\mathrm{~d}, J=8.7$ $\mathrm{Hz}, 1 \mathrm{H}), 8.16(\mathrm{dd}, J=8.1,1.5 \mathrm{~Hz}, 1 \mathrm{H}), 7.61(\mathrm{dd}, J=8.1$, $4.7 \mathrm{~Hz}, 1 \mathrm{H}), 7.54(\mathrm{~d}, J=2.5 \mathrm{~Hz}, 1 \mathrm{H}), 7.49(\mathrm{~d}, J=2.4 \mathrm{~Hz}$, $1 \mathrm{H}), 7.37(\mathrm{~s}, 1 \mathrm{H}), 4.42-4.37(\mathrm{~m}, 1 \mathrm{H}), 4.30(\mathrm{q}, J=7.2 \mathrm{~Hz}$, $1 \mathrm{H}), 3.62(\mathrm{~s}, 3 \mathrm{H}), 2.48-2.36(\mathrm{~m}, 2 \mathrm{H}), 2.17(\mathrm{~s}, 3 \mathrm{H}), 2.00(\mathrm{~s}$, $3 \mathrm{H}), 1.98-1.86(\mathrm{~m}, 2 \mathrm{H}), 1.21(\mathrm{~d}, J=7.2 \mathrm{~Hz}, 3 \mathrm{H}) .{ }^{13} \mathrm{C}$ NMR $\left(151 \mathrm{MHz}, \mathrm{DMSO}-d_{6}\right): \delta 172.93,172.58,165.95,156.10$, $148.80,147.53,139.70,139.68,139.07,135.95,131.85$, $131.74,131.44,128.30,127.28,127.06,126.39,111.09$, $52.45,51.16,49.54,31.59,30.91,18.35,18.09,15.04$. ESIHRMS calcd. For $\mathrm{C}_{26} \mathrm{H}_{26} \mathrm{BrCl}_{2} \mathrm{~N}_{6} \mathrm{O}_{5} \mathrm{~S}:[\mathrm{M}-\mathrm{H}]^{-}$683.0246, found 683.0237 .

Dimethyl\{2-[3-bromo-1-(3-chloropyridin-2-yl)-1H-pyrazole-5-carboxamido)-5-chloro-3-methylbenzoyl)-L-alanyl-L-aspartate (4i) White solid in 64\% yield; ${ }^{1} \mathrm{H}$ NMR $\left(600 \mathrm{MHz}, \mathrm{DMSO}-d_{6}\right): \delta 10.21(\mathrm{~s}, 1 \mathrm{H}), 8.47(\mathrm{~d}$, $J=4.7 \mathrm{~Hz}, 1 \mathrm{H}), 8.38(\mathrm{~d}, J=7.4 \mathrm{~Hz}, 1 \mathrm{H}), 8.33(\mathrm{~d}, J=8.0 \mathrm{~Hz}$, $1 \mathrm{H}), 8.15(\mathrm{dd}, J=8.1,1.5 \mathrm{~Hz}, 1 \mathrm{H}), 7.60(\mathrm{dd}, J=8.1,4.7 \mathrm{~Hz}$, $1 \mathrm{H}), 7.48(\mathrm{~d}, J=2.4 \mathrm{~Hz}, 1 \mathrm{H}), 7.45(\mathrm{dd}, J=7.3,2.5 \mathrm{~Hz}, 1 \mathrm{H})$, $7.36(\mathrm{~d}, J=3.0 \mathrm{~Hz}, 1 \mathrm{H}), 4.64(\mathrm{q}, J=6.6 \mathrm{~Hz}, 1 \mathrm{H}), 4.31(\mathrm{q}$, $J=7.3 \mathrm{~Hz}, 1 \mathrm{H}), 3.61(\mathrm{~s}, 3 \mathrm{H}), 3.58(\mathrm{~d}, J=9.6 \mathrm{~Hz}, 3 \mathrm{H}), 2.80$ $(\mathrm{dd}, J=16.4,6.2 \mathrm{~Hz}, 1 \mathrm{H}), 2.70(\mathrm{dd}, J=16.5,6.9 \mathrm{~Hz}, 1 \mathrm{H})$, $2.16(\mathrm{~s}, 3 \mathrm{H}), 1.17(\mathrm{~d}, J=7.4 \mathrm{~Hz}, 3 \mathrm{H}) .{ }^{13} \mathrm{C}$ NMR $(151 \mathrm{MHz}$, DMSO- $\left.d_{6}\right): \delta 172.59,171.43,170.92,170.88,165.88$, $156.05,148.83,147.53,139.68,139.09,135.95,131.84$, $131.77,131.39,128.32,127.24,127.05,126.35,111.10$, 52.68, 52.14, 49.02, 48.98, 35.96, 18.10, 18.01. ESI-HRMS 
calcd. For $\mathrm{C}_{26} \mathrm{H}_{24} \mathrm{BrCl}_{2} \mathrm{~N}_{6} \mathrm{O}_{7}:[\mathrm{M}-\mathrm{H}]^{-}$681.0267, found 681.0278 .

Methyl\{2-[3-bromo-1-(3-chloropyridin-2-yl)-1H-pyrazole-5-carboxamido)-5-chloro-3-methylbenzoyl)-L-alanyl-L-phenylalaninate (4j) White solid in $56 \%$ yield; ${ }^{1} \mathrm{H}$ NMR $\left(600 \mathrm{MHz}, \mathrm{DMSO}-d_{6}\right): \delta 10.22(\mathrm{~s}, 1 \mathrm{H}), 8.48(\mathrm{~d}$, $J=4.6 \mathrm{~Hz}, 1 \mathrm{H}), 8.30(\mathrm{t}, J=8.3 \mathrm{~Hz}, 2 \mathrm{H}), 8.15(\mathrm{~d}, J=7.9$ $\mathrm{Hz}, 1 \mathrm{H}), 7.60$ (dd, $J=6.7,4.7 \mathrm{~Hz}, 1 \mathrm{H}), 7.49(\mathrm{~s}, 1 \mathrm{H}), 7.38$ $(\mathrm{d}, J=4.0 \mathrm{~Hz}, 2 \mathrm{H}), 7.24(\mathrm{t}, J=7.7 \mathrm{~Hz}, 2 \mathrm{H}), 7.20(\mathrm{~d}, J=7.6$ $\mathrm{Hz}, 3 \mathrm{H}), 4.47$ (q, $J=7.4 \mathrm{~Hz}, 1 \mathrm{H}), 4.36(\mathrm{q}, J=7.3 \mathrm{~Hz}, 1 \mathrm{H})$, $3.58(\mathrm{~s}, 3 \mathrm{H}), 3.02(\mathrm{dd}, J=13.9,5.8 \mathrm{~Hz}, 1 \mathrm{H}), 2.94(\mathrm{dd}$, $J=13.9,8.6 \mathrm{~Hz}, 1 \mathrm{H}), 2.17(\mathrm{~s}, 3 \mathrm{H}), 1.15(\mathrm{dd}, J=7.1,1.5 \mathrm{~Hz}$, $3 \mathrm{H}) .{ }^{13} \mathrm{C}$ NMR (151 MHz, DMSO- $\left.d_{6}\right): \delta 173.42,173.30$, $172.46,172.35,165.61,156.31,156.00,148.85,147.52$, $139.66,136.05,131.78,131.37,130.56,128.34,127.88$, $127.22,127.03,126.28,115.41,115.33,111.09,54.28$, 54.03, 49.03, 36.63, 21.52, 18.48. ESI-HRMS calcd. For $\mathrm{C}_{30} \mathrm{H}_{26} \mathrm{BrCl}_{2} \mathrm{~N}_{6} \mathrm{O}_{5}:[\mathrm{M}-\mathrm{H}]^{-}$699.0525, found 699.0523.

Methyl\{2-[3-bromo-1-(3-chloropyridin-2-yl)-1H-pyrazole-5-carboxamido]-5-chloro-3-methylbenzoyl $\}$-L-ala$n y l$-L-tyrosinate (4k) White solid in $66 \%$ yield; ${ }^{1} \mathrm{H}$ NMR $\left(600 \mathrm{MHz}, \mathrm{DMSO}-d_{6}\right): \delta 10.23(\mathrm{~s}, 1 \mathrm{H}), 9.20(\mathrm{~d}, J=5.6 \mathrm{~Hz}$, $1 \mathrm{H}), 8.47(\mathrm{~s}, 1 \mathrm{H}), 8.31(\mathrm{~s}, 1 \mathrm{H}), 8.31-8.27(\mathrm{~m}, 1 \mathrm{H}), 8.23(\mathrm{~d}$, $J=7.4 \mathrm{~Hz}, 1 \mathrm{H}), 8.15(\mathrm{dd}, J=8.0,1.5 \mathrm{~Hz}, 1 \mathrm{H}), 7.60(\mathrm{dd}$, $J=8.1,4.7 \mathrm{~Hz}, 1 \mathrm{H}), 7.49(\mathrm{~s}, 1 \mathrm{H}), 7.42(\mathrm{dd}, J=15.3,2.5 \mathrm{~Hz}$, $1 \mathrm{H}), 7.37(\mathrm{~d}, J=4.5 \mathrm{~Hz}, 1 \mathrm{H}), 6.98(\mathrm{~d}, J=8.1 \mathrm{~Hz}, 2 \mathrm{H}), 6.63$ (t, $J=8.6 \mathrm{~Hz}, 2 \mathrm{H}), 4.45-4.28(\mathrm{~m}, 2 \mathrm{H}), 3.58(\mathrm{~d}, J=23.1 \mathrm{~Hz}$, $3 \mathrm{H}), 2.95-2.75(\mathrm{~m}, 2 \mathrm{H}), 2.17(\mathrm{~d}, J=2.9 \mathrm{~Hz}, 3 \mathrm{H}), 1.10(\mathrm{dd}$, $J=60.6,7.1 \mathrm{~Hz}, 3 \mathrm{H}) .{ }^{13} \mathrm{C}$ NMR $\left(151 \mathrm{MHz}, \mathrm{DMSO}-d_{6}\right)$ : $\delta$ 173.42, 173.30, 172.46, 172.35, 165.60, 156.31, 156.00, $148.85,147.52,139.67,139.05,136.05,131.78,131.37$, $130.56,128.34,127.22,127.03,126.28,115.41,115.33$, $111.09,54.28,54.03,49.03,36.63,21.52,18.11$. ESIHRMS calcd for $\mathrm{C}_{30} \mathrm{H}_{26} \mathrm{BrCl}_{2} \mathrm{~N}_{6} \mathrm{O}_{6}$ : $[\mathrm{M}-\mathrm{H}]^{-}$715.0474, found 715.0474.

\section{Synthesis of compound $5 a-k$}

Compounds $\mathbf{5 a}-\mathbf{k}$ were prepared with similar hydrolysis reactions as used to prepare compounds $\mathbf{3} \mathbf{a}$ and $\mathbf{3 b}$.

\{2-[3-Bromo-1-(3-chloropyridin-2-yl)-1H-pyrazole-5-carboxamido)-5-chloro-3-methylbenzoyljglycylglycine (5a) White solid in $90 \%$ yield; ${ }^{1} \mathrm{H}$ NMR $(600 \mathrm{MHz}$, DMSO $\left.-d_{6}\right): \delta 10.26(\mathrm{~d}, J=4.6 \mathrm{~Hz}, 1 \mathrm{H}), 8.64(\mathrm{~d}, J=5.5 \mathrm{~Hz}$, $1 \mathrm{H}), 8.49(\mathrm{~s}, 1 \mathrm{H}), 8.16(\mathrm{t}, J=6.3 \mathrm{~Hz}, 1 \mathrm{H}), 8.11(\mathrm{~d}, J=5.6$ $\mathrm{Hz}, 1 \mathrm{H}), 7.61(\mathrm{dd}, J=8.4,4.5 \mathrm{~Hz}, 1 \mathrm{H}), 7.53(\mathrm{~s}, 1 \mathrm{H}), 7.50$ (s, $1 \mathrm{H}), 7.33(\mathrm{~d}, J=4.6 \mathrm{~Hz}, 1 \mathrm{H}), 3.80-3.74(\mathrm{~m}, 4 \mathrm{H}), 2.17$ $(\mathrm{d}, J=4.6 \mathrm{~Hz}, 3 \mathrm{H}) .{ }^{13} \mathrm{C}$ NMR $\left(151 \mathrm{MHz}, \mathrm{DMSO}-d_{6}\right): \delta$ $171.51,169.47,166.66,156.24,148.73,147.56,139.90$,
$139.77,139.16,135.72,131.96,131.38,128.19,127.29$, $127.05,126.24,111.19,42.88,41.05,40.38,18.13$. ESIHRMS calcd. For $\mathrm{C}_{21} \mathrm{H}_{16} \mathrm{BrCl}_{2} \mathrm{~N}_{6} \mathrm{O}_{5}:[\mathrm{M}-\mathrm{H}]^{-}$580.9743, found 580.9753 .

\{2-[3-Bromo-1-(3-chloropyridin-2-yl)-1H-pyrazole-5-carboxamido)-5-chloro-3-methylbenzoyl)glycyl-L-alanine (5b) White solid in $85 \%$ yield; ${ }^{1} \mathrm{H}$ NMR $\left(600 \mathrm{MHz}, \mathrm{DMSO}-d_{6}\right): \delta 12.58(\mathrm{~s}, 1 \mathrm{H}), 10.24(\mathrm{~s}, 1 \mathrm{H})$, $8.52(\mathrm{t}, J=6.0 \mathrm{~Hz}, 1 \mathrm{H}), 8.49(\mathrm{~d}, J=4.7 \mathrm{~Hz}, 1 \mathrm{H}), 8.17(\mathrm{dd}$, $J=11.7,7.8 \mathrm{~Hz}, 2 \mathrm{H}), 7.60(\mathrm{dd}, J=8.2,4.8 \mathrm{~Hz}, 1 \mathrm{H}), 7.48$ $(\mathrm{d}, J=15.4 \mathrm{~Hz}, 2 \mathrm{H}), 7.34(\mathrm{~s}, 1 \mathrm{H}), 4.24(\mathrm{q}, J=7.3 \mathrm{~Hz}, 1 \mathrm{H})$, $3.85-3.73(\mathrm{~m}, 2 \mathrm{H}), 2.16(\mathrm{~s}, 3 \mathrm{H}), 1.27(\mathrm{~d}, J=7.2 \mathrm{~Hz}, 3 \mathrm{H})$. ${ }^{13} \mathrm{C}$ NMR (151 MHz, DMSO- $\left.d_{6}\right): \delta 172.55,172.48,172.31$, $165.79,165.72,156.03,148.84,147.53,139.68,139.16$, $136.15,131.77,131.41,128.33,127.22,127.04,126.31$, $111.14,54.96,49.05,18.33,18.11$. ESI-HRMS calcd. For $\mathrm{C}_{22} \mathrm{H}_{18} \mathrm{BrCl}_{2} \mathrm{~N}_{6} \mathrm{O}_{5}:[\mathrm{M}-\mathrm{H}]^{-}$594.9899, found 594.9901.

\{2-[3-Bromo-1-(3-chloropyridin-2-yl)-1H-pyrazole-5-carboxamido)-5-chloro-3-methylbenzoyl)glycyl-L-leucine (5c) White solid in $91 \%$ yield; ${ }^{1} \mathrm{H}$ NMR $\left(600 \mathrm{MHz}, \mathrm{DMSO}-d_{6}\right): \delta 12.56(\mathrm{~s}, 1 \mathrm{H}), 10.26(\mathrm{~s}, 1 \mathrm{H}), 8.52$ $(\mathrm{t}, J=5.9 \mathrm{~Hz}, 1 \mathrm{H}), 8.49(\mathrm{dd}, J=4.7,1.5 \mathrm{~Hz}, 1 \mathrm{H}), 8.17-8.13$ $(\mathrm{m}, 2 \mathrm{H}), 7.60(\mathrm{dd}, J=8.1,4.7 \mathrm{~Hz}, 1 \mathrm{H}), 7.50(\mathrm{~d}, J=2.5 \mathrm{~Hz}$, $1 \mathrm{H}), 7.48(\mathrm{~d}, J=2.5 \mathrm{~Hz}, 1 \mathrm{H}), 7.36(\mathrm{~s}, 1 \mathrm{H}), 4.30-4.22(\mathrm{~m}$, $1 \mathrm{H}), 3.83(\mathrm{dd}, J=16.6,6.0 \mathrm{~Hz}, 1 \mathrm{H}), 3.76(\mathrm{dd}, J=16.6,5.8$ $\mathrm{Hz}, 1 \mathrm{H}), 2.16(\mathrm{~s}, 3 \mathrm{H}), 1.66-1.58(\mathrm{~m}, 1 \mathrm{H}), 1.54-1.50(\mathrm{~m}$, $2 \mathrm{H}), 0.87(\mathrm{~d}, J=6.6 \mathrm{~Hz}, 3 \mathrm{H}), 0.83(\mathrm{~d}, J=6.5 \mathrm{~Hz}, 3 \mathrm{H}) .{ }^{13} \mathrm{C}$ NMR (151 MHz, DMSO- $\left.d_{6}\right): \delta 174.38,169.00,166.45$, $156.14,148.75,147.53,139.85,139.74,139.28,135.75$, $132.01,131.94,131.38,128.20,127.27,127.02,126.17$, $111.18,50.70,42.60,40.55,24.75,23.29,21.85,18.16$. ESIHRMS calcd. For $\mathrm{C}_{25} \mathrm{H}_{24} \mathrm{BrCl}_{2} \mathrm{~N}_{6} \mathrm{O}_{5}:[\mathrm{M}-\mathrm{H}]^{-}$637.0369, found 637.0383 .

\{2-[3-Bromo-1-(3-chloropyridin-2-yl)-1H-pyrazole-5-carboxamido)-5-chloro-3-methylbenzoyl)glycyl-L-valine (5d) White solid in $89 \%$ yield; ${ }^{1} \mathrm{H}$ NMR $\left(600 \mathrm{MHz}, \mathrm{DMSO}-d_{6}\right): \delta 10.31(\mathrm{~s}, 1 \mathrm{H}), 8.34(\mathrm{dd}, J=4.8$, $1.6 \mathrm{~Hz}, 1 \mathrm{H}), 7.91(\mathrm{dd}, J=8.1,1.6 \mathrm{~Hz}, 1 \mathrm{H}), 7.82(\mathrm{~s}, 1 \mathrm{H})$, $7.40-7.35(\mathrm{~m}, 2 \mathrm{H}), 7.29(\mathrm{~d}, J=2.3 \mathrm{~Hz}, 1 \mathrm{H}), 7.18(\mathrm{~d}, J=9.0$ $\mathrm{Hz}, 1 \mathrm{H}), 7.00(\mathrm{~s}, 1 \mathrm{H}), 4.31$ (dd, $J=9.0,4.7 \mathrm{~Hz}, 1 \mathrm{H}), 4.25$ (dd, $J=15.2,6.7 \mathrm{~Hz}, 1 \mathrm{H}), 3.68(\mathrm{dd}, J=15.1,5.3 \mathrm{~Hz}, 1 \mathrm{H})$, $2.18(\mathrm{~s}, 3 \mathrm{H}), 2.15-2.07(\mathrm{~m}, J=4.9 \mathrm{~Hz}, 1 \mathrm{H}), 0.89$ (d, $J=6.9$ $\mathrm{Hz}, 3 \mathrm{H}), 0.80(\mathrm{~d}, J=6.9 \mathrm{~Hz}, 3 \mathrm{H}) .{ }^{13} \mathrm{C}$ NMR $(151 \mathrm{MHz}$, DMSO- $\left.d_{6}\right): \delta 174.38,169.00,166.45,156.14,148.75$, $147.53,139.85,139.74,139.28,135.75,132.01,131.94$, $131.38,128.20,127.27,127.02,126.17,111.18,50.70$, 42.60, 24.75, 23.29, 21.85, 18.16. ESI-HRMS calcd. For $\mathrm{C}_{24} \mathrm{H}_{22} \mathrm{BrCl}_{2} \mathrm{~N}_{6} \mathrm{O}_{5}:[\mathrm{M}-\mathrm{H}]^{-}$623.0212, found 623.0212. 
\{2-[3-Bromo-1-(3-chloropyridin-2-yl)-1H-pyrazole-5-carboxamido)-5-chloro-3-methylbenzoyl)glycyl-L-serine (5e) White solid in 87\% yield; ${ }^{\mathbf{1}} \mathbf{H}$ NMR (600 $\left.\mathrm{MHz}, \mathrm{DMSO}-d_{6}\right) \delta 10.24(\mathrm{~s}, 1 \mathrm{H}), 8.49(\mathrm{~d}, J=4.1 \mathrm{~Hz}, 1 \mathrm{H})$, $8.16(\mathrm{~d}, J=8.1 \mathrm{~Hz}, 1 \mathrm{H}), 8.10(\mathrm{~d}, J=7.9 \mathrm{~Hz}, 1 \mathrm{H}), 7.60(\mathrm{dd}$, $J=8.2,4.7 \mathrm{~Hz}, 1 \mathrm{H}), 7.50(\mathrm{~s}, 1 \mathrm{H}), 7.45(\mathrm{~s}, 1 \mathrm{H}), 7.36(\mathrm{~s}, 1 \mathrm{H})$, $4.31(\mathrm{dt}, J=8.4,4.7 \mathrm{~Hz}, 1 \mathrm{H}), 3.85(\mathrm{qd}, J=16.7,6.0 \mathrm{~Hz}$, $2 \mathrm{H}), 3.71(\mathrm{dd}, J=11.0,5.0 \mathrm{~Hz}, 1 \mathrm{H}), 3.62(\mathrm{dd}, J=11.0,4.2$ $\mathrm{Hz}, 1 \mathrm{H}), 2.16$ (s, 3H). ${ }^{13} \mathrm{C}$ NMR (151 MHz, DMSO- $d_{6}$ ): $\delta 171.51,169.47,166.66,156.24,148.73,147.56,139.91$, $139.77,139.16,135.72,131.96,131.38,128.19,127.29$, $127.05,126.24,111.19,42.88,41.05,40.38,18.13$. ESIHRMS calcd. For $\mathrm{C}_{22} \mathrm{H}_{18} \mathrm{BrCl}_{2} \mathrm{~N}_{6} \mathrm{O}_{6}$ : $[\mathrm{M}-\mathrm{H}]^{-}$610.9848, found 610.9845 .

\{2-[3-Bromo-1-(3-chloropyridin-2-yl)-1H-pyrazole-5-carboxamido)-5-chloro-3-methylbenzoyl\}-L-alanylglycine (5f) White solid in 93\% yield; ${ }^{1} \mathrm{H}$ NMR $(600$ $\left.\mathrm{MHz}, \mathrm{DMSO}-d_{6}\right): \delta 10.24(\mathrm{~s}, 1 \mathrm{H}), 8.48(\mathrm{dd}, J=4.8,1.5 \mathrm{~Hz}$, $1 \mathrm{H}), 8.46(\mathrm{~d}, J=7.3 \mathrm{~Hz}, 1 \mathrm{H}), 8.16(\mathrm{dd}, J=8.1,1.5 \mathrm{~Hz}, 1 \mathrm{H})$, $8.10(\mathrm{t}, J=5.9 \mathrm{~Hz}, 1 \mathrm{H}), 7.60(\mathrm{dd}, J=8.1,4.7 \mathrm{~Hz}, 1 \mathrm{H}), 7.51$ (dd, $J=19.1,2.4 \mathrm{~Hz}, 2 \mathrm{H}), 7.35(\mathrm{~s}, 1 \mathrm{H}), 4.31(\mathrm{q}, J=7.2 \mathrm{~Hz}$, $1 \mathrm{H}), 3.73(\mathrm{~d}, J=5.9 \mathrm{~Hz}, 2 \mathrm{H}), 2.18(\mathrm{~s}, 3 \mathrm{H}), 1.20$ (d, $J=7.2$ $\mathrm{Hz}, 3 \mathrm{H}) .{ }^{13} \mathrm{C}$ NMR $\left(151 \mathrm{MHz}, \mathrm{DMSO}-d_{6}\right): \delta 172.55$, $172.48,172.31,165.79,165.72,156.03,148.84,147.53$, $139.68,139.16,136.15,131.77,131.41,128.33,127.22$, $127.04,126.31,111.14,54.96,49.05,18.33$, 18.11. ESIHRMS calcd. For $\mathrm{C}_{22} \mathrm{H}_{18} \mathrm{BrCl}_{2} \mathrm{~N}_{6} \mathrm{O}_{5}:[\mathrm{M}-\mathrm{H}]^{-}$594.9899, found 594.9896.

\{2-[3-Bromo-1-(3-chloropyridin-2-yl)-1H-pyrazole-5-carboxamido]-5-chloro-3-methylbenzoyl\}-L-alanyl-L-alanine (5g) White solid in $91 \%$ yield; ${ }^{1} \mathrm{H}$ NMR $\left(600 \mathrm{MHz}, \mathrm{DMSO}-d_{6}\right): \delta 10.25(\mathrm{~s}, 1 \mathrm{H}), 8.48(\mathrm{dd}, J=4.7$, $1.5 \mathrm{~Hz}, 1 \mathrm{H}), 8.36$ (d, $J=7.4 \mathrm{~Hz}, 1 \mathrm{H}), 8.16$ (dd, $J=8.1,1.6$ $\mathrm{Hz}, 1 \mathrm{H}), 8.13$ (d, $J=7.5 \mathrm{~Hz}, 1 \mathrm{H}), 7.60$ (dd, $J=8.1,4.7 \mathrm{~Hz}$, $1 \mathrm{H}), 7.49(\mathrm{~s}, 2 \mathrm{H}), 7.36(\mathrm{~s}, 1 \mathrm{H}), 4.34(\mathrm{q}, J=7.2 \mathrm{~Hz}, 1 \mathrm{H}), 4.21$ (q, $J=7.3 \mathrm{~Hz}, 1 \mathrm{H}), 2.17(\mathrm{~s}, 3 \mathrm{H}), 1.24(\mathrm{~d}, J=7.3 \mathrm{~Hz}, 3 \mathrm{H})$, 1.19 (d, $J=7.2 \mathrm{~Hz}, 3 \mathrm{H}) .{ }^{13} \mathrm{C}$ NMR $\left(151 \mathrm{MHz}\right.$, DMSO- $\left.d_{6}\right)$ : $\delta 174.39,172.20,165.79,156.03,148.80,147.53,139.74$, $139.69,139.06,135.95,131.83,131.81,131.37,128.29$, 127.23, 127.04, 126.39, 111.10, 49.19, 47.92, 18.44, 18.11, 17.77. ESI-HRMS calcd. For $\mathrm{C}_{23} \mathrm{H}_{20} \mathrm{BrCl}_{2} \mathrm{~N}_{6} \mathrm{O}_{5}:[\mathrm{M}-\mathrm{H}]^{-}$ 609.0056, found 609.0041.

\{2-[3-Bromo-1-(3-chloropyridin-2-yl)-1H-pyrazole-5-carboxamido)-5-chloro-3-methylbenzoyl)-L-alanyl-L-methionine (5h) White solid in $86 \%$ yield; ${ }^{1} \mathrm{H}$ NMR $\left(600 \mathrm{MHz}, \mathrm{DMSO}-d_{6}\right): \delta 12.58(\mathrm{~s}, 1 \mathrm{H}), 10.22(\mathrm{~s}$, $1 \mathrm{H}), 8.48(\mathrm{~d}, J=4.8 \mathrm{~Hz}, 1 \mathrm{H}), 8.37(\mathrm{~d}, J=7.4 \mathrm{~Hz}, 1 \mathrm{H}), 8.15$ $(\mathrm{t}, J=8.1 \mathrm{~Hz}, 2 \mathrm{H}), 7.60(\mathrm{dd}, J=7.9,5.0 \mathrm{~Hz}, 1 \mathrm{H}), 7.48(\mathrm{~s}$, $1 \mathrm{H}), 7.44(\mathrm{~s}, 1 \mathrm{H}), 7.37(\mathrm{~s}, 1 \mathrm{H}), 4.38-4.28(\mathrm{~m}, 2 \mathrm{H}), 2.49-$ $2.39(\mathrm{~m}, 2 \mathrm{H}), 2.16(\mathrm{~s}, 3 \mathrm{H}), 2.02(\mathrm{~s}, 3 \mathrm{H}), 2.00-1.94(\mathrm{~m}$,
1H), $1.90-1.82(\mathrm{~m}, 1 \mathrm{H}), 1.20(\mathrm{~d}, J=7.1 \mathrm{~Hz}, 3 \mathrm{H}) .{ }^{13} \mathrm{C}$ NMR $\left(151 \mathrm{MHz}, \mathrm{DMSO}-d_{6}\right): \delta 173.65,172.66,165.87,156.01$, 148.86, 147.53, 139.68, 139.66, 139.01, 136.08, 131.77, $131.39,130.10,128.34,127.24,127.04,126.42,111.06$, 51.13, 49.50, 31.20, 30.08, 18.45, 18.10, 15.06. ESI-HRMS calcd. For $\mathrm{C}_{25} \mathrm{H}_{24} \mathrm{BrCl}_{2} \mathrm{~N}_{6} \mathrm{O}_{5} \mathrm{~S}:[\mathrm{M}-\mathrm{H}]^{-}$669.0089, found 669.0085 .

\{2-[3-Bromo-1-(3-chloropyridin-2-yl)-1H-pyrazole-5-carboxamido)-5-chloro-3-methylbenzoyl)- $L$ -alanyl-L-aspartic acid (5i) White solid in 85\% yield; ${ }^{1} \mathrm{H}$ NMR (600 MHz, DMSO- $\left.d_{6}\right): \delta 12.54(\mathrm{~s}, 2 \mathrm{H}), 10.21$ (s, $1 \mathrm{H}), 8.48(\mathrm{~d}, J=4.8 \mathrm{~Hz}, 1 \mathrm{H}), 8.35(\mathrm{t}, J=6.5 \mathrm{~Hz}, 1 \mathrm{H})$, $8.20(\mathrm{t}, J=6.6 \mathrm{~Hz}, 1 \mathrm{H}), 8.16(\mathrm{~d}, J=8.0 \mathrm{~Hz}, 1 \mathrm{H}), 7.60(\mathrm{dd}$, $J=7.9,4.9 \mathrm{~Hz}, 1 \mathrm{H}), 7.49(\mathrm{~s}, 1 \mathrm{H}), 7.45(\mathrm{~s}, 1 \mathrm{H}), 7.38(\mathrm{~s}, 1 \mathrm{H})$, $4.54(\mathrm{q}, J=6.8 \mathrm{~Hz}, 1 \mathrm{H}), 4.35(\mathrm{q}, J=7.1 \mathrm{~Hz}, 1 \mathrm{H}), 2.74-2.65$ $(\mathrm{m}, 1 \mathrm{H}), 2.62-2.53(\mathrm{~m}, 1 \mathrm{H}), 2.17(\mathrm{~s}, 3 \mathrm{H}), 1.17(\mathrm{t}, J=8.8$ $\mathrm{Hz}, 3 \mathrm{H}) .{ }^{13} \mathrm{C}$ NMR $\left(151 \mathrm{MHz}, \mathrm{DMSO}-d_{6}\right): \delta 172.59$, $171.43,170.92,170.88,165.88,156.05,148.83,147.53$, $139.68,139.09,135.95,131.84,131.77,131.39,128.32$, 127.24, 127.05, 126.35, 111.10, 52.68, 52.14, 49.02, 18.10, 18.01. ESI-HRMS calcd. For $\mathrm{C}_{24} \mathrm{H}_{20} \mathrm{BrCl}_{2} \mathrm{~N}_{6} \mathrm{O}_{7}:[\mathrm{M}-\mathrm{H}]^{-}$ 652.9954, found 652.9950 .

\{2-[3-Bromo-1-(3-chloropyridin-2-yl)-1H-pyrazole-5-carboxamido)-5-chloro-3-methylbenzoyl)-L -alanyl-L-phenylalanine (5j) White solid in 79\% yield; ${ }^{1} \mathrm{H}$ NMR (600 MHz, DMSO- $\left.d_{6}\right): \delta 12.79(\mathrm{~s}, 1 \mathrm{H}), 10.22$ $(\mathrm{s}, 1 \mathrm{H}), 8.47(\mathrm{~d}, J=4.8 \mathrm{~Hz}, 1 \mathrm{H}), 8.22(\mathrm{~d}, J=7.5 \mathrm{~Hz}, 1 \mathrm{H})$, $8.18(\mathrm{~d}, J=8.3 \mathrm{~Hz}, 1 \mathrm{H}), 8.15(\mathrm{~d}, J=8.1 \mathrm{~Hz}, 1 \mathrm{H}), 7.60(\mathrm{dd}$, $J=8.1,4.9 \mathrm{~Hz}, 1 \mathrm{H}), 7.48(\mathrm{~s}, 1 \mathrm{H}), 7.40(\mathrm{~d}, J=2.6 \mathrm{~Hz}, 1 \mathrm{H})$, $7.37(\mathrm{~s}, 1 \mathrm{H}), 7.24-7.16(\mathrm{~m}, 5 \mathrm{H}), 4.46(\mathrm{td}, J=9.0,4.5 \mathrm{~Hz}$, $1 \mathrm{H}), 4.32(\mathrm{q}, J=7.2 \mathrm{~Hz}, 1 \mathrm{H}), 3.08$ (dd, $J=13.8,4.7 \mathrm{~Hz}$, $1 \mathrm{H}), 2.87$ (dd, $J=13.7,9.6 \mathrm{~Hz}, 1 \mathrm{H}), 2.16(\mathrm{~s}, 3 \mathrm{H}), 1.01$ $(\mathrm{d}, J=7.1 \mathrm{~Hz}, 3 \mathrm{H}) .{ }^{13} \mathrm{C}$ NMR $\left(151 \mathrm{MHz}\right.$, DMSO $\left.-d_{6}\right): \delta$ $173.30,172.38,165.59,156.00,148.85,147.52,139.67$, $139.05,137.89,136.01,131.79,131.35,129.66,129.63$, $128.58,128.52,128.34,127.22,127.04,126.84,126.31$, 111.09, 53.67, 49.07, 37.34, 18.41, 18.11. ESI-HRMS calcd. For $\mathrm{C}_{29} \mathrm{H}_{24} \mathrm{BrCl}_{2} \mathrm{~N}_{6} \mathrm{O}_{5}:[\mathrm{M}-\mathrm{H}]^{-}$685.0369, found 685.0366.

\{2-[3-Bromo-1-(3-chloropyridin-2-yl)-1H-pyrazole-5-carboxamido]-5-chloro-3-methylbenzoyl $\}$-L-alanyl-L-tyrosine (5k) White solid in $88 \%$ yield; ${ }^{1} \mathrm{H}$ NMR $\left(600 \mathrm{MHz}, \mathrm{DMSO}-d_{6}\right): \delta 12.68(\mathrm{~s}, 1 \mathrm{H}), 10.24(\mathrm{~s}, 1 \mathrm{H}), 9.18$ (s, $1 \mathrm{H}), 8.48$ (dd, $J=4.6,1.5 \mathrm{~Hz}, 1 \mathrm{H}), 8.31(\mathrm{~s}, 1 \mathrm{H}), 8.15$ (d, $J=8.1 \mathrm{~Hz}, 1 \mathrm{H}), 8.07(\mathrm{dd}, J=63.5,8.0 \mathrm{~Hz}, 1 \mathrm{H}), 7.60$ (dd, $J=8.1,4.7 \mathrm{~Hz}, 1 \mathrm{H}), 7.49$ (s, $1 \mathrm{H}), 7.41$ (dd, $J=11.6$, $2.5 \mathrm{~Hz}, 1 \mathrm{H}), 7.38(\mathrm{~d}, J=5.1 \mathrm{~Hz}, 1 \mathrm{H}), 6.99(\mathrm{dd}, J=8.3,4.9$ $\mathrm{Hz}, 2 \mathrm{H}), 6.62(\mathrm{t}, J=8.3 \mathrm{~Hz}, 2 \mathrm{H}), 4.39-4.30(\mathrm{~m}, 2 \mathrm{H}), 2.91$ (dd, $J=13.9,5.3 \mathrm{~Hz}, 1 \mathrm{H}), 2.78$ (ddd, $J=36.8,13.9,8.8 \mathrm{~Hz}$, $1 \mathrm{H}), 2.16(\mathrm{~s}, 3 \mathrm{H}), 1.09$ (dd, $J=65.8,7.1 \mathrm{~Hz}, 3 \mathrm{H}) .{ }^{13} \mathrm{C}$ NMR 
$\left(151 \mathrm{MHz}, \mathrm{DMSO}-d_{6}\right): \delta 173.27,172.45,165.78,156.31$, $156.08,148.81,147.52,139.67,139.13,136.08,131.81$, $131.67,130.54,128.31,127.81,127.26,127.05,126.24$, $115.44,115.36,111.12$, 79.55, 54.28, 54.04, 49.07, 40.39, 18.15, 18.09. ESI-HRMS calcd. For $\mathrm{C}_{29} \mathrm{H}_{24} \mathrm{BrCl}_{2} \mathrm{~N}_{6} \mathrm{O}_{6}$ : $[\mathrm{M}-\mathrm{H}]^{-}$701.0318, found 701.0311.

\section{Determination of phloem mobility Plant materials}

Castor bean seeds (Ricinus communis L.) No. 9 were purchased from the Agricultural Science Academy (Zibo, China) and nurtured in wet absorbent cotton for $24 \mathrm{~h}$ at $27 \pm 1{ }^{\circ} \mathrm{C}$ prior to sowing in vermiculite watered with tap water. Seedlings were grown at $27 \pm 1{ }^{\circ} \mathrm{C}$ and $80 \% \pm 5 \%$ $\mathrm{RH}$ during the photoperiod $(14 \mathrm{~h})$ for 6 days.

\section{Screening of phloem mobility}

The already described procedure [30] was utilized to the phloem sap collection. After endosperms being carefully stripped off, cotyledons were incubated in buffered solution containing $20 \mathrm{mM}$ 4-morpholineethanesulfonic acid (MES) $(\mathrm{pH}=5.0), 0.25 \mathrm{mM} \mathrm{MgCl}_{2}$, and $0.5 \mathrm{mM} \mathrm{CaCl}_{2}$ for $0.5 \mathrm{~h}$, then immediately transferred to a new MES culture fluid containing $100 \mu \mathrm{M}$ of the test compounds. After the cotyledons were incubated for $2 \mathrm{~h}$, the hypocotyls were severed in the hook region for phloem exudation, and the phloem sap was continually collected for $2 \mathrm{~h}$.

\section{Analytical methods}

After dilution with methanol (phloem sap/methanol $=1: 4, \mathrm{v} / \mathrm{v}$ ), the collected phloem sap was analyzed on high-performance liquid chromatograph (HPLC, Agilent 1290 series) equipped with a UV detector at $210 \mathrm{~nm}$. Separations were done on a $\mathrm{SB}-\mathrm{C}_{18}$ reversed-phase column (5 $\mu \mathrm{m}, 250 \times 4.6 \mathrm{~mm}$ i.d.; Agilent) with a flow rate of 1.0 $\mathrm{mL} / \mathrm{min}$ at $30{ }^{\circ} \mathrm{C}$, and the eluent was made of acetonitrile and water containing $0.1 \%$ trifluoroethanoic acid (TFA). The calibration curves of the test compounds (ranging from 0 to $100 \mu \mathrm{M}$ ) were linear.

\section{Calculation of physicochemical properties}

The physicochemical properties of all conjugates and chlorantraniliprole, including ionization constant in aqueous solution $\left(\mathrm{p} K_{\mathrm{a}}\right)$ and octanol/water partitioning coefficient $\left(\log K_{o / w}\right)$, were predicted by ACD LogD software suite version 14.0 [31].

\section{Biological assay in vitro}

The insecticidal activities of compounds $\mathbf{4 g}$ and $\mathbf{5 g}$ against Plutella xylostella L. and Spodoptera exigua were tested according to literature [6], and the insecticidal activity of chlorantraniliprole was also tested as positive control. Leaf-disc dipping assays were employed with petri dishes kept in incubator at $26{ }^{\circ} \mathrm{C}$ and $85 \%$ relative humidity under a photoperiod of $16 \mathrm{~h}: 8 \mathrm{~h}$ (light/dark). Mortalities were checked after treated for $48 \mathrm{~h}$.

\section{Results and discussion \\ Phloem mobility in $R$. communis}

Phloem mobilities of all dipeptide conjugates were studied in $R$. communis, which is an ideal model to investigate the phloem mobility of xenobiotics [10, 12, 32]. An interesting observation was that the methyl ester structure on compounds $\mathbf{4 a - k}$ were mostly hydrolyzed to their corresponding acidic conjugates during the uptake and transport process in planta. When $R$. communis cotyledons were treated with dipeptide methyl ester conjugates $\mathbf{4 a -}$ $\mathbf{k}$, the concentrations of tested compound in phloem sap were close to the limit of detection, and only corresponding dipeptide conjugates $\mathbf{5 a}-\mathbf{k}$ were detected by HPLC. Therefore, the phloem mobility of the dipeptide methyl ester conjugates $\mathbf{4 a - k}$ was represented by the amount of corresponding dipeptide conjugates being detected.

Results from systemicity tests demonstrated that the non-phloem-mobile chlorantraniliprole could acquire phloem mobility by conjugating with dipeptide or dipeptide methyl ester structures. As shown in Fig. 1, both the dipeptide methyl ester conjugates $\mathbf{4 a} \mathbf{a}-\mathbf{k}$ and corresponding dipeptide conjugates $\mathbf{5 a}-\mathbf{k}$ were able to be absorbed by cotyledons of $R$. communis, while the parent insecticide chlorantraniliprole could not be detected in the phloem sap. Especially, the concentrations of compounds $\mathbf{4 a}-\mathbf{k}$ in phloem sap (in forms of hydrolysis products) were generally higher than that of corresponding dipeptide conjugates $\mathbf{5 a} \mathbf{- k}$. In particular, compound $\mathbf{4 g}$ represented the highest concentration $(114.49 \pm 11.10 \mu \mathrm{M})$ under the existing experimental conditions in the form of its hydrolysis product $\mathbf{5 g}$, which has exceeded its concentration in incubation solution $(100 \mu \mathrm{M})$. There was no significant difference between the detected concentrations of $\mathbf{4 b}, \mathbf{4 c}, \mathbf{4 d}, \mathbf{4 f}, \mathbf{4 h}, \mathbf{4 i}$, all of which were significantly lower than that of conjugate $\mathbf{4 g}$.

In addition to the difference between acids and esters, the side chain groups on dipeptide residues also showed effects on phloem mobility of dipeptide-chlorantraniliprole conjugates. By comparing the difference between the uptake amounts of the conjugates, it was found that the substituent $R$ at the $\alpha$ position in the amino acid structure was related to the transport of the conjugate in plants. When $\mathrm{R}=$ methyl, the conjugate showed the best phloem mobility. When the size of substituent group gradually increase, the phloem mobility of the conjugate would decrease. The conjugates carrying aromatic rings on the side chain, such as $\mathbf{4 j}$ and $\mathbf{4 k}$, exhibited the lowest concentration in the phloem sap. It 


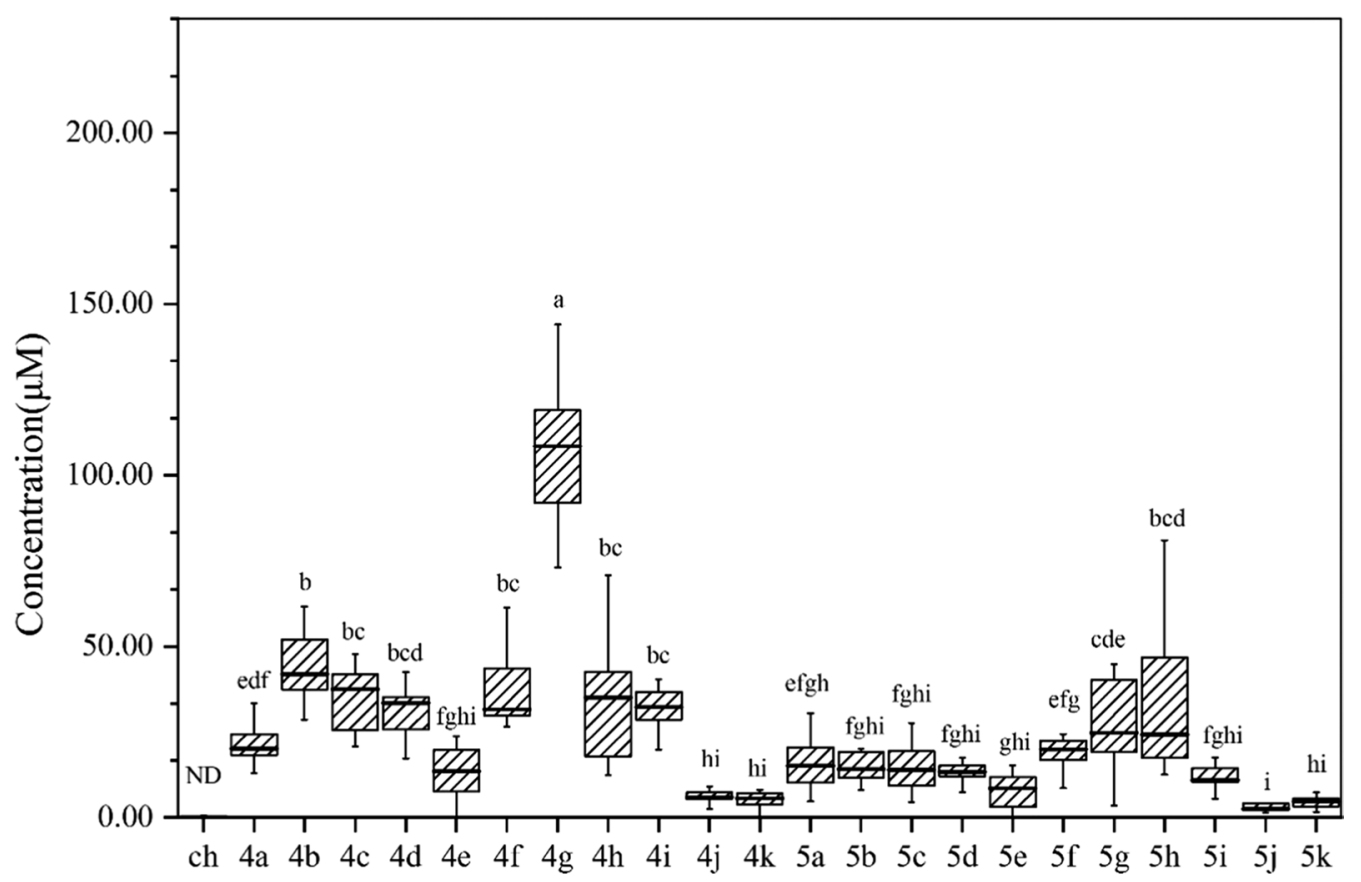

Compounds

Fig. 1 Concentrations of different dipeptide conjugates in phloem sap of Ricinus communis. Cotyledons were incubated in incubation solution contain $100 \mu \mathrm{M}$ of tested compound. The phloem sap collection started $30 \mathrm{~min}$ after pre-incubation and lasted for $2 \mathrm{~h}$. Duncan's multiple-range tests at a $5 \%$ probability level were used to determine statistical differences among treatments $(P<0.05)$. Ch chlorantraniliprole, ND not detected. The data (mean $\pm S E, n=10$ ) with a column topped by different letters are significantly different from each other

demonstrated that the dipeptides with aromatic ring on the side chain was less effective on improving the phloem uptake.

\section{Predicted phloem mobility}

Our previous research indicated that the phloem mobility of pesticide-nutrient conjugates could be influenced by their physicochemical properties and affinities with active carrier systems, which can affect the efficiency of passive diffusion and active transportation respectively $[6,8,11]$. In order to further interpret the structure-phloem mobility relationship of dipeptidechlorantraniliprole conjugates, their physicochemical properties were first calculated and analyzed. For each conjugate, ionization constant in aqueous solution $\left(\mathrm{p} K_{\mathrm{a}}\right)$ and octanol/water partitioning coefficient $\left(\log K_{\mathrm{o} / \mathrm{w}}\right)$ were predicted (Table 1).

Results showed no obvious correlation between phloem systemicity and $\log K_{\mathrm{o} / \mathrm{w}}$ values. Compared to the significant differences among phloem mobilities of conjugates, the range fluctuation of $\log K_{\mathrm{o} / \mathrm{w}}$ values was small. The $\mathrm{p} K_{\mathrm{a}}$ and $\log K_{\mathrm{o} / \mathrm{w}}$ values were then fitted in Kleier model, which was widely applied to predict the phloem mobility of xenobiotics [33, 34]. As shown in Fig. 2, the data points for all dipeptide ester conjugates $\mathbf{4 a} \mathbf{a}-\mathbf{k}$ were located in non-phloem-mobile area, which was not consistent with the experimental data. It was speculated that dipeptide derivatives were loaded into the phloem of plants via pathways other than passive diffusion, possibly with the participation of dipeptide transporters [35]. Although some of the dipeptide acid conjugates $(\mathbf{5 a}, \mathbf{5 b}, \mathbf{5 e}, \mathbf{5 g}, \mathbf{5 f}$, and $5 \mathbf{i}$ ) showed data points located in phloem-mobile area, their phloem uptake was not significantly improved compared with the ones located in non-phloem-mobile area. This indicated that passive diffusion could help the conjugates to penetrate into phloem tissue [11], but was not the major route for the uptake process. In summary, active transport may play a dominant role in the uptake and transport of dipeptide conjugates. It is possible that by linking dipeptide fragments with pesticide structure, the conjugates will be able to bind with dipeptide transporters, and thus process phloem mobility.

\section{Insecticidal activity}

Insecticidal activities of compound $\mathbf{4 g}$, which represented the highest phloem mobility in $R$. communis, and its hydrolysis product $\mathbf{5 g}$ were tested against $\mathrm{Plu}$ tella xylostella L. and Spodoptera exigua according to methods reported in literature [36]. The insecticidal activity of chlorantraniliprole was also tested as positive 
Table 1 Molecular weights, $\log K_{o / w}$ and $\mathrm{p} K_{\mathrm{a}}$ of compounds 4a-5k

\begin{tabular}{|c|c|c|c|}
\hline Compounds & $\begin{array}{l}\text { Molecular weight } \\
\text { (g/mol) }\end{array}$ & $\log K_{o / w}$ & $\mathrm{p} K_{\mathrm{a}}$ \\
\hline $4 a$ & 598.23 & 3.48 & $10.33 \pm 0.7$ \\
\hline $4 b$ & 612.26 & 3.72 & $10.33+0.7$ \\
\hline $4 c$ & 654.34 & 4.5 & $10.33+0.7$ \\
\hline $4 d$ & 640.31 & 4.28 & $10.33+0.7$ \\
\hline $4 e$ & 628.26 & 3.04 & $10.33 \pm 0.7$ \\
\hline $4 f$ & 612.26 & 3.72 & $10.33 \pm 0.7$ \\
\hline $4 \mathrm{~g}$ & 626.29 & 4.06 & $10.33 \pm 0.7$ \\
\hline $4 \mathrm{~h}$ & 686.4 & 4.6 & $10.33 \pm 0.7$ \\
\hline $4 i$ & 684.32 & 4.47 & $10.33 \pm 0.7$ \\
\hline $4 j$ & 702.38 & 5.94 & $10.33 \pm 0.7$ \\
\hline $4 k$ & 718.38 & 5.21 & $9.75 \pm 0.15$ \\
\hline $5 a$ & 584.21 & 1.04 & $3.29 \pm 0.1$ \\
\hline $5 b$ & 598.23 & 1.37 & $3.38 \pm 0.1$ \\
\hline $5 c$ & 640.31 & 2.42 & $3.36 \pm 0.1$ \\
\hline $5 d$ & 626.29 & 1.88 & $3.32 \pm 0.1$ \\
\hline $5 e$ & 614.23 & 0.3 & $2.97 \pm 0.1$ \\
\hline $5 f$ & 598.23 & 1.29 & $3.3 \pm 0.1$ \\
\hline $5 g$ & 612.26 & 1.71 & $3.39 \pm 0.1$ \\
\hline $5 \mathrm{~h}$ & 672.38 & 2.26 & $3.21 \pm 0.1$ \\
\hline $5 i$ & 656.27 & 0.02 & $2.85 \pm 0.1$ \\
\hline $5 j$ & 688.36 & 3.06 & $3.49 \pm 0.1$ \\
\hline $5 k$ & 704.36 & 2.29 & $3.07 \pm 0.1$ \\
\hline
\end{tabular}

control. As shown in Table 2, both compounds $\mathbf{4 g}$ and $5 \mathrm{~g}$ maintained good biological activity against Plutella xylostella L. and Spodoptera exigua comparable to chlorantraniliprole. Compared to compound $\mathbf{4 g}$, compound $\mathbf{5 g}$ showed significantly better control effect against Plutella xylostella $\mathrm{L}$. and similar insecticidal activity against Spodoptera exigua. Considering the compound $\mathbf{4 g}$ could be hydrolyzed into the compound $\mathbf{5 g}$ and accumulate in phloem sap during the transportation process in planta, application of the ester conjugate $\mathbf{4 g}$ could potentially decrease the usage of pesticides while showing similar control effect on sucking pests compared to commercial chlorantraniliprole.

\section{Conclusion}

In summary, 22 new dipeptide-chlorantraniliprole conjugates were synthesized via simple synthetic route. All derivatives have acquired phloem mobility in R. communis compared to non-phloem-mobile chlorantraniliprole, which proved that dipeptides could be another option for promoiety when designing new phloem-mobile pesticides. The uptaken amounts of most dipeptide ester conjugates in phloem were better than that of corresponding dipeptide conjugates, while the dipeptide

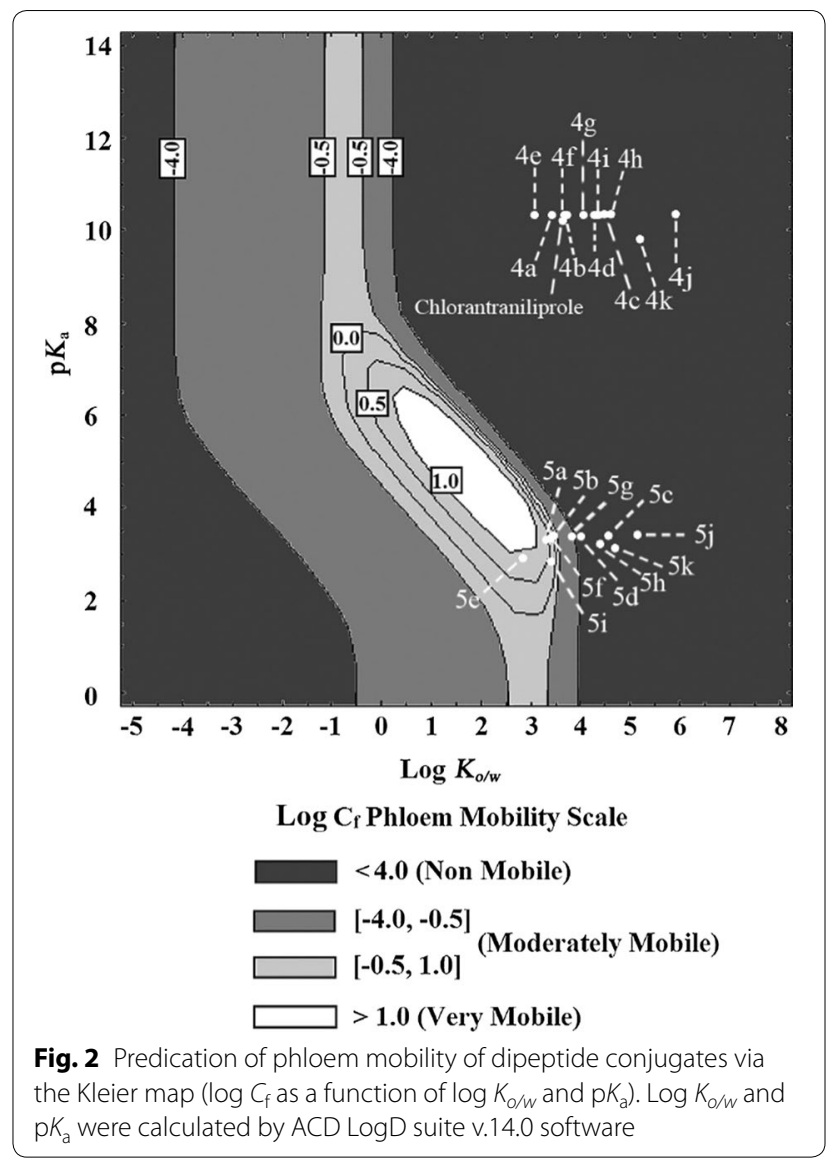

Table 2 Insecticidal activities of compounds $4 \mathrm{~g}$, $\mathbf{5 g}$ and chlorantraniliprole (50 $\mathrm{mg} / \mathrm{L})$ against Plutella xylostella L. and Spodoptera exigua in $48 \mathrm{~h}$

\begin{tabular}{lll}
\hline Compounds & Mortality (\%) \\
\cline { 2 - 3 } & Plutella xylostella L. & Spodoptera exigua \\
\hline $\mathbf{4 g}$ & $54.58 \pm 3.03^{\mathrm{a}}$ & $76.21 \pm 7.63^{\mathrm{a}}$ \\
$\mathbf{5 g}$ & $87.58 \pm 2.89^{\mathrm{b}}$ & $83.57 \pm 4.46^{\mathrm{ab}}$ \\
Chlorantraniliprole & $91.67 \pm 4.81^{\mathrm{b}}$ & $97.22 \pm 2.78^{\mathrm{b}}$ \\
\hline
\end{tabular}

Test concentration was $50 \mathrm{mg} / \mathrm{L}$. Duncan tests at a $5 \%$ probability level were used to determine statistical differences among treatments $(P<0.05)$

esters would be hydrolyzed to corresponding dipeptides during the uptake or transportation process. In particular, compound $\mathbf{4 g}$ that conjugated with alanyl-alanine dipeptide fragment showed the highest phloem mobility among all conjugates, and could lead to high concentration of $5 \mathbf{g}$ in phloem sap which exceeded its concentration in incubation solution. Bioassay results showed that the control effects of $\mathbf{4 g}$ and $\mathbf{5 g}$ against Plutella xylostella L. and Spodoptera exigua were comparable to that of chlorantraniliprole. Thus, application of compound 
$4 \mathrm{~g}$ could potentially lead to better in vitro control effect compared to chlorantraniliprole. Further research on the uptake mechanism of dipeptide-chlorantraniliprole conjugates and its affinity with dipeptide transporters is still in progress.

\section{Abbreviations}

$\mathrm{CH}_{2} \mathrm{Cl}_{2}$ : Dichloromethane; DMAP: N, N-dimethyl-4-aminopyridine; EDCl: 1-(3-Dimethylaminopropyl)-3-ethylcarbodiimide hydrochloride; $\mathrm{HCl}$ : Hydrochloric acid; HPLC: High-performance liquid chromatography; LiOH: Lithium hydroxide; log $K_{\text {ow }}$ : Octanol/water partitioning coefficient; MES: 4-Morpholineethanesulfonic acid; NMM: N-methyl morpholine; $\mathrm{p} K_{\mathrm{a}}$ : Ionization constant in aqueous solution; TLC: Thin-layer chromatography; TFA: Trifluoroacetic acid; THF: Tetrahydrofuran; UV: Ultraviolet.

\section{Acknowledgements}

We were grateful to Prof. Ri-Yuan Tang for guidance in organic synthesis.

\section{Authors' contributions}

$\mathrm{HHX}$ and SJZ designed the protocol of the study; SJZ synthesized the compounds, analyzed the results, and wrote the manuscript; XML performed the uptake experiment; HXW and CZ coordinated the study and revised the manuscript. All authors read and approved the final manuscript.

\section{Funding}

The authors would like to thank the National Key R\&D Program of China (Grant No. 2018YFD0200300, 2017YFD0200307), the National Natural Science Foundation of China (Grant No. 31672044), and the Scientific Project in Guangzhou City (Grant No. 201707020013).

\section{Availability of data and materials}

The datasets used and/or analyzed during the current study are available from the corresponding author on reasonable request.

\section{Competing interests}

The authors declare that they have no competing interests.

Received: 23 April 2019 Accepted: 9 March 2020

Published online: 30 March 2020

\section{References}

1. Birch ANE, Begg GS, Squire GR (2011) How agro-ecological research helps to address food security issues under new IPM and pesticide reduction policies for global crop production systems. J Exp Bot 62(10):3251-3261

2. Wang CJ, Liu ZQ (2007) Foliar uptake of pesticides_-present status and future challenge. Pestic Biochem Physiol 87(1):1-8

3. Wu H, Marhadour S, Lei Z, Yang W, Marivingt-Mounir C, Bonnemain JL, Chollet JF (2016) Vectorization of agrochemicals: amino acid carriers are more efficient than sugar carriers to translocate phenylpyrrole conjugates in the Ricinus system. Environ Sci Pollut Res 25(15):14336-14349.

4. Marhadour S, Wu H, Yang W, Marivingt-Mounir C, Bonnemain JL, Chollet JF (2017) Vectorisation of agrochemicals via amino acid carriers: influence of the spacer arm structure on the phloem mobility of phenylpyrrole conjugates in the Ricinus system. Pest Manag Sci 73(9):1972-1982

5. Yang W, Wu H, Xu H, Hu A, Lu M (2011) Synthesis of glucose-fipronil conjugate and its phloem mobility. J Agric Food Chem 59(23):12534-12542

6. Yao G, Wen Y, Zhao C, Xu H (2017) Novel amino acid ester-chlorantraniliprole conjugates: design, synthesis, phloem accumulation and bioactivity. Pest Manag Sci 73(10):2131-2137

7. Chen Y, Lei ZW, Zhang Y, Yang W, Liu HF, Zhou YF, Yang MF (2017) Influence of pyranose and spacer arm structures on phloem mobility and insecticidal activity of new tralopyril derivatives. Molecules 22(7):1058

8. Xie Y, Zhao J, Wang C, Yu A, Liu N, Chen L, Lin F, Xu H (2016) Glycinergicfipronil uptake is mediated by an amino acid carrier system and induces the expression of amino acid transporter genes in Ricinus communis seedlings. J Agric Food Chem 64(19):3810-3818
9. Wang J, Lei Z, Wen Y, Mao G, Wu H, Xu H (2014) A novel fluorescent conjugate applicable to visualize the translocation of glucose-fipronil. J Agric Food Chem 62(35):8791-8798

10. Wu H, Yang W, Zhang Z, Huang T, Yao G, Xu H (2012) Uptake and phloem transport of glucose-fipronil conjugate in Ricinus communis involve a carrier-mediated mechanism. J Agric Food Chem 60(24):6088-6094

11. Sheng Q, Liu X, Xie Y, Lin F, Zhang Z, Zhao C, Xu H (2018) Synthesis of novel amino acid-fipronil conjugates and study on their phloem loading mechanism. Molecules 23(4):778

12. Chollet JF, Rocher F, Jousse C, Deletage-Grandon C, Bashiardes G, Bonnemain $J \mathrm{~L}$ (2004) Synthesis and phloem mobility of acidic derivatives of the fungicide fenpiclonil. Pest Manag Sci 60(11):1063-1072

13. Kleier DA, Hsu FC (1996) Phloem mobility of xenobiotics: VII. The design of phloem systemic pesticides. Weed Sci 44(3):749-756

14. Jiang X, Xie Y, Ren Z, Ganeteg U, Lin F, Zhao C, Xu H (2018) Design of a new glutamine-fipronil conjugate with $a$-amino acid function and its uptake by A. thaliana Lysine Histidine Transporter 1 (AtLHT1). J Agric Food Chem 66(29):7597-7605

15. Wu H, Xu H, Marivingt-Mounir C, Bonnemain JL, Chollet JF (2018) Vectorizing agrochemicals: enhancing bioavailability via carrier-mediated transport. Pest Manag Sci 75(6):1507-1516

16. Steiner HY, Song W, Zhang L, Naider F, Becker JM, Stacey G (1994) An Arabidopsis peptide transporter is a member of a new class of membrane transport proteins. Plant Cell 6(9):1289-1299

17. Paulsen IT, Skurray RA (1994) The POT family of transport proteins. Trends Biochem Sci 19(10):404

18. Steiner H, Naider F, Becker JM (1995) The PTR family: a new group of peptide transporters. Mol Microbiol 16(5):825-834

19. Newstead S (2011) Towards a structural understanding of drug and peptide transport within the proton-dependent oligopeptide transporter (POT) family. Biochem Soc Trans 39(5):1353-1358

20. Biegel A, Knüetter I, Hartrodt B, Gebauer S, Theis S, Luckner P, Kottra G, Rastetter M, Zebisch K, Thondorf I, Daniel H, Neubert K, Brandsch M (2006) The renal type $\mathrm{H}^{+}$/peptide symporter PEPT2: structure-affinity relationships. Amino Acids 31(2):137-156

21. Zhang L, Zhang L, Luo T, Zhou J, Sun L, Xu Y (2012) Synthesis and evaluation of a dipeptide-drug conjugate library as substrates for PEPT1. ACS Comb Sci 14(2):108-114

22. Rubioaliaga I, Daniel H (2002) Mammalian peptide transporters as targets for drug delivery. Trends Pharmacol Sci 23(9):434-440

23. Dubowchik GM, Firestone RA, Padilla L, Willner D, Hofstead SJ, Mosure K, Knipe JO, Lasch SJ, Trail PA (2002) Cathepsin B-labile dipeptide linkers for lysosomal release of doxorubicin from internalizing immunoconjugates: model studies of enzymatic drug release and antigen-specific in vitro anticancer activity. Bioconjug Chem 13(4):855-869

24. Shi J, Ren G, Wu N, Weng J, Xu T, Liu X, Tan C (2017) Design, synthesis and insecticidal activities of novel anthranilic diamides containing polyfluoroalkyl pyrazole moiety. Chin Chem Lett 28(8):1727-1730

25. Feng Q, Liu Z, Xiong L, Wang M, Li Y, Li Z (2010) Synthesis and insecticidal activities of novel anthranilic diamides containing modified $n$-pyridylpyrazoles. J Agric Food Chem 58(23):12327-12336

26. Fang Y, Wu C, Larock RC, Shi F (2011) Synthesis of 2 H-indazoles by the [3+2] dipolar cycloaddition of sydnones with arynes. J Org Chem 76(21):8840-8851

27. Lu H, Zhang F, Meng X, Duan S, Xiao W (2009) Enantioselective Michael reactions of $\beta$, $\beta$-disubstituted nitroalkenes: a new approach to $\beta$-2,2-amino acids with hetero-quaternary stereocenters. Org Lett 11(17):3946-3949

28. Babij NR, Mccusker EO, Whiteker GT, Canturk B, Choy N, Creemer LC, De Amicis CV, Hewlett NM, Johnson PL, Knobelsdorf JA, Li F, Lorsbach BA, Nugent BM, Ryan SJ, Smith MR, Yang Q (2016) NMR chemical shifts of trace impurities: industrially preferred solvents used in process and green chemistry. Org Process Res Dev 20(3):661-667

29. Quideau S, Lyvinec G, Marguerit M, Bathany K, Ozanne-Beaudenon A, Buffeteau T, Cavagnat D, Chenede A (2009) Asymmetric hydroxylative phenol dearomatization through in situ generation of iodanes from chiral iodoarenes and m-CPBA. Angew Chem Int Ed 48(25):4605-4609

30. Rocher F, Chollet JF, Jousse C, Bonnemain JL (2006) Salicylic acid, an ambimobile molecule exhibiting a high ability to accumulate in the phloem. Plant Physiol 141(4):1684-1693 
31. Rocher F, Chollet JF, Legros S, Jousse C, Lemoine R, Faucher M, Bush DR, Bonnemain JL (2009) Salicylic acid transport in Ricinus communis involves a $\mathrm{pH}$-dependent carrier system in addition to diffusion. Plant Physiol 150(4):2081-2091

32. Deletage-Grandon C, Chollet JF, Faucher M, Rocher F, Komor E, Bonnemain JL (2001) Carrier-mediated uptake and phloem systemy of a 350-Dalton chlorinated xenobiotic with an $\alpha$-amino acid function. Plant Physiol 125(4):1620-1632

33. Kleier DA (1988) Phloem mobility of xenobiotics: I. Mathematical model unifying the weak acid and intermediate permeability theories. Plant Physiol 86(3):803-810

34. Brudenell AJP, Baker DA, Grayson BT (1995) Phloem mobility of xenobiotics: tabular review of physicochemical properties governing the output of the Kleier model. Plant Growth Regul 16(3):215-231
35. Tegeder M, Rentsch D (2010) Uptake and partitioning of amino acids and peptides. Mol Plant 3(6):997-1011

36. Xia Q, Wen YJ, Wang H, Li YF, Xu HH (2014) $\beta$-Glucosidase involvement in the bioactivation of glycosyl conjugates in plants: synthesis and metabolism of four glycosidic bond conjugates in vitro and in vivo. J Agric Food Chem 62(46):11037-11046

\section{Publisher's Note}

Springer Nature remains neutral with regard to jurisdictional claims in published maps and institutional affiliations.
Ready to submit your research? Choose BMC and benefit from:

- fast, convenient online submission

- thorough peer review by experienced researchers in your field

- rapid publication on acceptance

- support for research data, including large and complex data types

- gold Open Access which fosters wider collaboration and increased citations

- maximum visibility for your research: over $100 \mathrm{M}$ website views per year

At BMC, research is always in progress.

Learn more biomedcentral.com/submissions 